\title{
Evaluation of the Role of Multiple Hydrogen Bonding in Offering Stability to Negative Ion Adducts in Electrospray Mass Spectrometry
}

\author{
Yang Cai, Monica C. Concha, Jane S. Murray, and Richard B. Cole \\ Department of Chemistry, University of New Orleans, New Orleans, Louisiana, USA
}

\begin{abstract}
An experimental approach, electrospray mass spectrometry (ES-MS), and a theoretical approach employing computer modeling, have been used to characterize the interaction between small inorganic anions and neutral analyte molecules that form anionic adduct species in negative mode ES mass spectrometry. Certain anionic adducts of small saccharides (e.g., $\alpha$-D-glucose, sucrose) have shown exceptional stability in ES mass spectra even when internal energies are raised at high "cone" voltages. Computer modeling studies reveal that multiple hydrogen bonding strengthens the interaction between these neutral molecules and the attaching anion. The equilibrium structures and stabilization energies of these anionic adducts have been evaluated by semi-empirical, ab initio, and density functional theory (DFT) methods. Chloride anion is found to be capable of forming "bridging" hydrogen bonds between monosaccharide rings of polysaccharides resulting in the stabilization of chloride adducts, thus reducing the tendency for the glycosidic bond to decompose. Moreover, the tendency for various hydroxyl hydrogens on saccharide molecules to dissociate in the form of $\mathrm{HA}\left(\mathrm{A}^{-}\right.$, anion) during decomposition of anionic adducts, thereby forming $[\mathrm{M}-\mathrm{H}]^{-}$, has also been evaluated by computer modeling. (J Am Soc Mass Spectrom 2002, 13, 1360-1369) () 2002 American Society for Mass Spectrometry
\end{abstract}

$\mathrm{A}$ nionic adducts comprised of a small inorganic anion attached to a neutral analyte molecule are important sources of signal in negative ion electrospray mass spectrometry (ES-MS). For those compounds that do not form $[\mathrm{M}-\mathrm{H}]^{-}$readily without the aid of a base, creation of an anionic adduct with a small inorganic anion will be an alternative means of ionization in negative mode ES-MS. A few small anions, namely chloride [1-4] and cyanide [5-8], have been used to generate anionic adducts for ES-MS studies. The formation and decomposition of chloride adducts have been further investigated from a thermodynamic standpoint [9-12]. However, the conditions that favor the formation and survival of anionic adducts have not been extensively defined and are not fully understood. Moreover, the interactions between neutral analyte molecules and the attaching small inorganic anions have not been fully characterized.

Various mass spectrometry methods have been applied to probe the interactions between ions and neutral analyte molecules [13-15]. These methods typically evaluate enthalpies of ion-molecule reactions or unimo-

Published online October 24, 2002

Address reprint requests to Dr. R. B. Cole, Department of Chemistry, University of New Orleans, 2000 Lakeshore Drive, New Orleans, LA 70148 , USA. E-mail: rcole@uno.edu lecular dissociations of ionic adducts to derive gasphase thermodynamic properties such as bond energies and ion affinities. In some cases, the nature of the ion-molecule interaction could be further elucidated by determining the difference in the entropy changes for competing decomposition pathways $[16,17]$. To date, the vast majority of ion-molecule interaction studies performed by mass spectrometry focus on positive ion studies of cationic adduct species, especially protonated molecules [14] and alkali metal adducts [18-21]. Dication adduct species, such as alkaline earth metal [22] and transition metal [23] adducts of oligosaccharides have also been explored. Small inorganic anions attaching to neutral analyte molecules, on the other hand, have received far less research attention. However, a few studies employing anion attachment in negative ion ES-MS have appeared, such as reports on iodide attachment to acetone [24], chloride attachment to saccharides [1, 10-12], and cyanide attachment (including covalent) to fullerenes $[6,8]$. In order to gain insight into the exact nature of the interactions between neutral analyte molecules and attaching small inorganic anions that are responsible for negative ion adduct formation and stabilization, two complementary approaches have been employed in the current study. The first examines ES-MS spectra of anionic adducts obtained under a variety of conditions, while the second uses computa- 
Table 1. Total energies calculated at the B3PW91/6-311+ $\mathrm{G}^{*}$ level $\mathrm{l}^{\mathrm{a}, \mathrm{b}, \mathrm{c}}$

\begin{tabular}{lc||lcc}
\hline Species & $\begin{array}{c}\text { Total energy } \\
\text { (hartrees) }\end{array}$ & $\alpha$-D-glucose adduct & $\begin{array}{c}\text { Total energy (hartrees) } \\
\text { of stable adduct }\end{array}$ & $\begin{array}{c}\text { Total energy (hartrees) } \\
\text { of "transition state"d }\end{array}$ \\
\hline \hline $\mathrm{F}^{-}$ & -99.84586 & Fluoride adduct & -787.03742 & $-786.98864^{\mathrm{e}}$ \\
$\mathrm{Cl}^{-}$ & -460.24517 & Chloride adduct structure (a) & -1147.39173 & $-1147.38652^{\mathrm{f}}$ \\
$\mathrm{Br}^{-}$ & -2574.21722 & Chloride adduct structure (b) & -1147.38950 & $-1147.34423^{\mathrm{e}}$ \\
$\mathrm{HF}$ & -100.43304 & Chloride adduct structure (c) & -1147.39790 & $-1147.34291^{\mathrm{e}}$ \\
$\mathrm{M}(\alpha \mathrm{Gggg} g)$ & -687.09811 & Bromide adduct & -3261.35673 & $-3261.32743^{\mathrm{e}}$ \\
{$[\mathrm{M}-\mathrm{H}]^{-}\left(\alpha \mathrm{G}_{1} g \overline{g g} x\right)$} & -686.54733 & & & \\
\hline
\end{tabular}

${ }^{\text {a }} \mathrm{M}$ is $\alpha$-D glucose.

bomenclature of $\alpha$-D-glucose conformer is explained in Appendix.

${ }^{\mathrm{c}} 1$ hartree $=2625 \mathrm{~kJ} / \mathrm{mol}$.

d"Transition states" were obtained by QST3 calculations. Frequency calculations were performed at the HF/6-31G level, and one imaginary frequency was found to accompany each "transition state".

"The forces have converged, however the displacements have not, suggesting that the energy curve in this region is very flat. We examined the normal mode corresponding to the one imaginary frequency, and it appeared that the halide anion (or fluoride leaving as HF) was moving toward and away from $\alpha$-D-glucose. This motion suggests that the "transition state" is along the decomposition reaction coordinate.

fThe forces and displacements have both converged.

tional methods to estimate stabilization energies and equilibrium structures for those adduct species that exhibit exceptional stability in the gas phase.

\section{Experimental}

\section{Mass Spectrometry}

Commercially purchased chemicals used in this study were dissolved in methanol/water $=9: 1(\mathrm{vol} / \mathrm{vol})$ without further purification. All mass spectra were acquired on a Quattro II triple quadrupole mass spectrometer (Micromass, Inc., Manchester, UK) equipped with an electrospray source. Sample solutions were introduced into the electrospray source at a flow rate of $2-4 \mu \mathrm{L} / \mathrm{min}$ via a metal capillary that was held at high negative voltage $(-2.0$ to $-3.0 \mathrm{kV})$. Nitrogen gas was used as both nebulizing gas and drying gas to aid droplet break up and desolvation. Collision induced dissociation (CID) was performed under single collision conditions by introducing low-pressure argon gas (0.10.2 mTorr) into the collision cell, and collision energies were adjusted to nearly identical values in the centerof-mass frame of reference $\left(E_{\text {com }}\right)$ for all anionic adducts involved in comparison studies.

\section{Computational Studies}

The structures of anionic adduct species and their decomposition products were constructed and then optimized via PC SPARTAN Plus version 2.0 [25] on a Gateway (Poway, CA) x86 PC computer. An energy minimizer based on the MMFF94 [26] force field was used to refine the preliminary structure during the structure template construction. The lowest-energy conformer (the global minimum) search was achieved via MMFF94 molecular mechanics in conjunction with the Monte Carlo method [27]. Other low-energy conformers were determined by the same searching method adding certain indicated constraints to the same preliminary structure template. All low-energy conformer struc- tures were further optimized first by semi-empirical (AM1) [28], and then by ab initio $\left(\mathrm{HF} / 6-31+\mathrm{G}^{*}\right)$ [29] calculations. Any constraints added prior to a MMFF94 conformer search in preparation for AM1 optimization were not imposed for subsequent $a b$ initio and DFT optimizations.

The above-mentioned procedure generated input structures for more sophisticated DFT geometry optimizations using Gaussian 98 [30]; these calculations were performed on an IBM-RS-6000 workstation. The functionals employed were the Becke three-parameter hybrid (B3) [31] for exchange, and the Perdew-Wang (PW 91) [32] for correlation, using the $6-311+\mathrm{G}^{*}$ basis set. The final structures and related total energies (electronic energies at $0 \mathrm{~K}$ ) were obtained from the DFT full geometry optimizations at the B3PW91/6-311+ $\mathrm{G}^{*}$ level; these total energies are listed in Table 1. For each type of calculation, the multiplicity was set to 1 for all species, and the charge state was set to -1 for all anionic species and 0 for all neutral species. The $\Delta \mathrm{E}$ values for the dissociation of the $\alpha$-D-glucose halide adducts (obtained using the total energies in Table 1) are given in Table 2, where $\Delta \mathrm{E}$ is equal to the sum of the energies of the products minus the energy of the reactant (anionic adduct), for each reaction in Table 2 . The validity of using $\Delta \mathrm{E}$ values derived from thermodynamically stable structures to represent the actual energy required for decomposition hinges upon the approximation that the dissociation pathway exhibits zero reverse activation barrier.

To evaluate possible activation barriers, transition state calculations for the decomposition of anionic adducts were performed using quadratic synchronous guided transition-state optimization (QST3) [33] at the B3PW91/6-311+ $\mathrm{G}^{*}$ level provided by the Gaussian 98 program. The results are listed in Table 1, and the energy differences ( $\Delta E^{\prime}$ values) between the optimized anionic adducts and the respective decomposition "transition states" are listed in Table 2. 
Table 2. Multiple hydrogen bonding in $\alpha$-D-glucose halide adducts ${ }^{\mathrm{a}}$ modeled by B3PW91/6-311+ $\mathrm{G}^{*}$

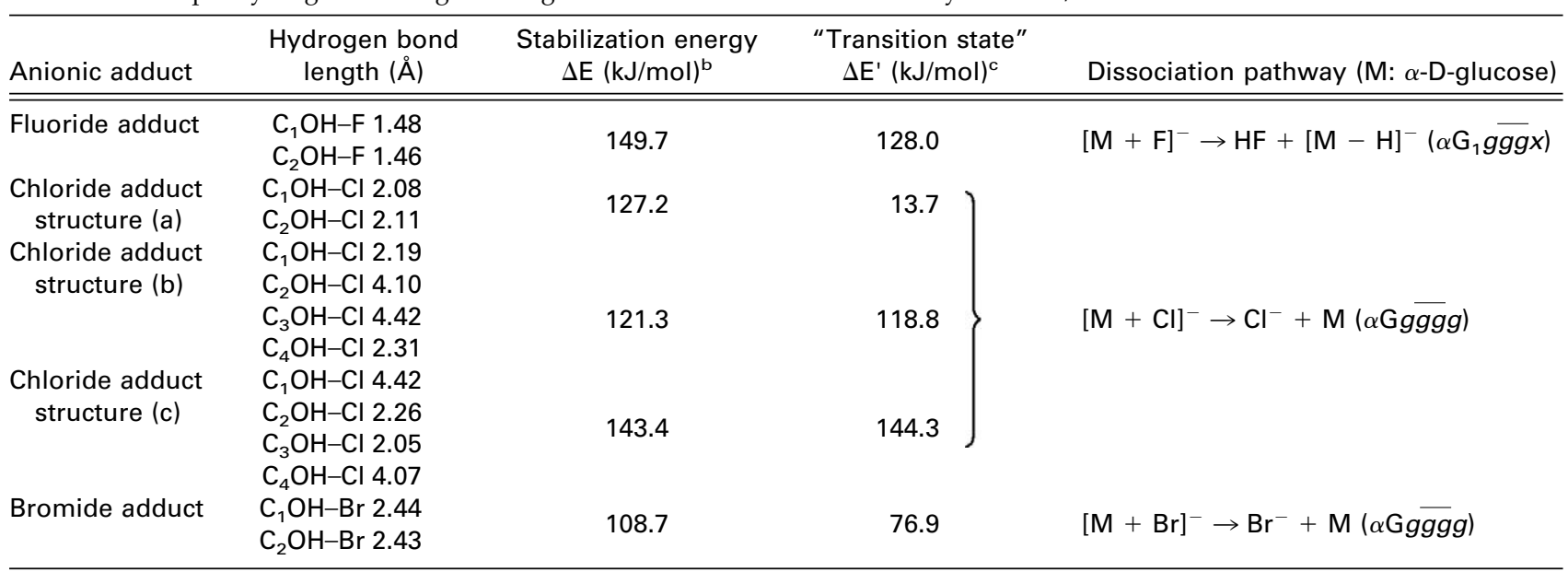

${ }^{\mathrm{a}} \mathrm{M}$ is $\alpha$-D-glucose. Nomenclature of $\alpha$-D-glucose conformer is explained in Appendix.

bTotal energy difference between the stable adduct and its decomposition products.

cTotal energy difference between the stable adduct and the "transition state".

\section{Results and Discussion}

Electrospray is considered to be a "soft" ionization technique for mass spectrometry, and many weakly bound (non-covalent) adduct species can be observed in ES-MS under certain conditions, such as when a low "cone voltage" or "nozzle-skimmer" voltage difference is employed. In the electrospray source, low cone voltages can promote dissociation of cluster ions, while elevated values lead to covalent bond cleavage via so-called "in-source" or "nozzle-skimmer" collision induced dissociation [34]. Adduct species, such as small inorganic anions attaching to neutral analyte molecules, may decompose when subjected to collisions, because the electrostatic interaction between the ion and neutral is relatively weak. However, some very stable anionic adducts were observed to survive at high cone voltages in our investigations of selected sucrose adducts. Various cone voltages were employed when acquiring ES mass spectra of a sample solution comprised of $1 \mathrm{mM}$ sucrose and equimolar amounts $(0.01 \mathrm{mM})$ of six ammonium salts: ammonium fluoride $\left(\mathrm{NH}_{4} \mathrm{~F}\right)$, ammonium chloride $\left(\mathrm{NH}_{4} \mathrm{Cl}\right)$, ammonium acetate $\left(\mathrm{CH}_{3} \mathrm{COONH}_{4}\right)$, ammonium bromide $\left(\mathrm{NH}_{4} \mathrm{Br}\right)$, ammonium sulphate $\left(\mathrm{NH}_{4}\right)_{2} \mathrm{SO}_{4}$, and ammonium trifluoroacetate (TFA) $\left(\mathrm{CF}_{3} \mathrm{COONH}_{4}\right)$ in methanol/water $=9: 1(\mathrm{vol} / \mathrm{vol})(\mathrm{pH}$ reads 6.8 at $25{ }^{\circ} \mathrm{C}$, no correction for organic content). At low cone voltage $(15 \mathrm{~V})$, all six anions yielded anionic adducts with sucrose (Figure 1a). Additional peaks at $\mathrm{m} / \mathrm{z} 387$ (possibly formate or ethoxide adduct of sucrose) and $\mathrm{m} / \mathrm{z} 431$ (sucrose adduct with $\mathrm{C}_{4} \mathrm{H}_{9} \mathrm{O}_{2}^{-}$that originated from methanol [1]) also appeared. As the cone voltage was increased ( $30 \mathrm{~V}$, Figure $1 \mathrm{~b}$ ), the abundances of all adducts decreased relative to [M $\mathrm{H}]^{-}$, and the fragment ion resulting from glycosidic bond cleavage of sucrose (Scheme 1) appeared at $\mathrm{m} / \mathrm{z}$ 179. At even higher cone voltage (45 V, Figure 1c), the energy imparted to the ionic species was further raised, resulting in an increased tendency for cleavage of the glycosidic bond thereby forming $\mathrm{m} / \mathrm{z} 179$. Significantly, even with this higher internal energy uptake, the chloride adduct and the bisulphate adduct of sucrose still survive while other anionic adducts almost disappear (Figure 1c). The electrostatic interaction between chloride (or bisulphate) and sucrose in the gas phase thus appears to be exceptionally strong, but we do not anticipate a stronger interaction than that of the cova-

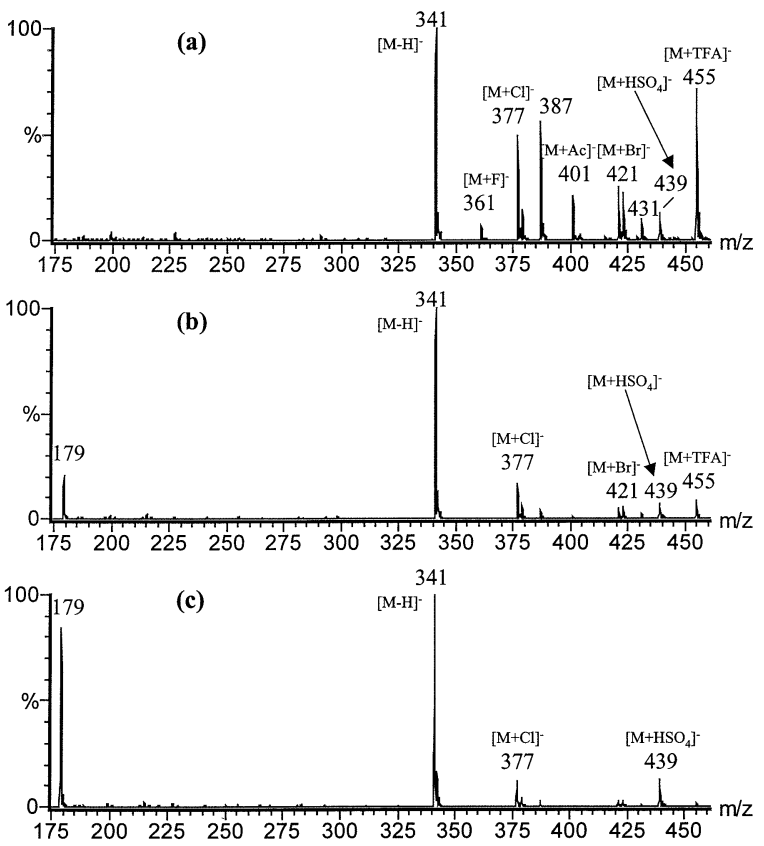

Figure 1. Negative ion electrospray mass spectra of sucrose (1 $\mathrm{mM}$ ) in the presence of ammonium salts of fluoride, chloride, acetate, bromide, sulphate and trifluoroacetate (TFA) $(0.01 \mathrm{mM}$ each). (a) At low cone voltage ( $15 \mathrm{~V})$ all six anionic adducts can be seen in the spectrum; $(\mathbf{b})$ cone voltage $=30 \mathrm{~V} ;(\mathbf{c})$ at high cone voltage $(45 \mathrm{~V})$, the peak corresponding to breakage of the covalent glycosidic bond $(\mathrm{m} / \mathrm{z} 179)$ is prominent, but chloride and bisulphate adducts still survive. 


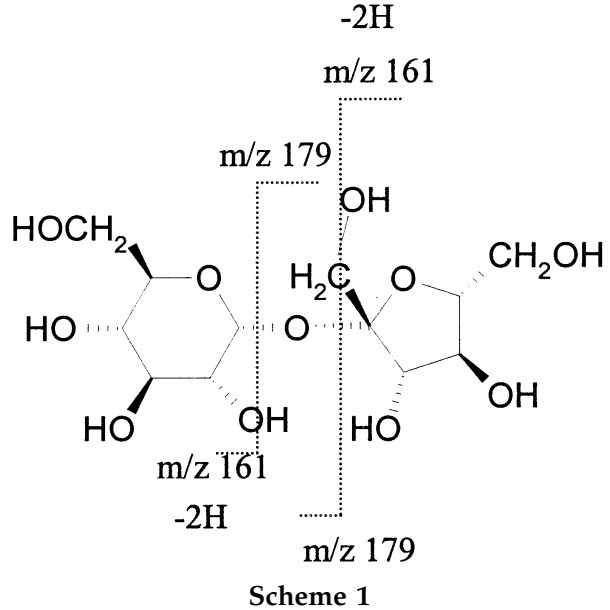

lent glycosidic bond. In addition to sucrose, $\alpha$-D-glucose [12] and xylose have also been found to form very stable adducts with chloride or bisulphate in preference to other tested anions $\left(\mathrm{F}^{-}, \mathrm{CH}_{3} \mathrm{COO}^{-}, \mathrm{Br}^{-}\right.$, and $\mathrm{CF}_{3} \mathrm{COO}^{-}$) in the electrospray source. The strength of the anion-neutral interaction and the three-dimensional structure of the adduct need to be elucidated in order to better define the underlying forces that are responsible for the exceptional stability of these anionic adducts.

Tandem mass spectrometry is a refined experimental approach to examine the stabilities of gas-phase anionic adducts. When an anionic adduct of the form M. . . ${ }^{-}$ decomposes in the collision cell of a tandem mass spectrometer under very low-energy conditions, it may dissociate via one of two pathways forming either [M $\mathrm{H}]^{-}+\mathrm{HA}$ or alternatively, $\mathrm{M}+\mathrm{A}^{-}$depending on the relative magnitude of the gas-phase bacisities of the anion $\left([\mathrm{A}]^{-}\right)$and the deprotonated organic molecule $\left([\mathrm{M}-\mathrm{H}]^{-}\right)$. The gas-phase basicity of an anion is defined as the negative of the free energy released from the combination of the anion and a proton. If the gas-phase basicity of $[\mathrm{A}]^{-}$is larger than that of $[\mathrm{M}-$ $\mathrm{H}]^{-}$, then the decomposition pathway leading to the production of $[\mathrm{M}-\mathrm{H}]^{-}$is favored, otherwise the production of $[\mathrm{A}]^{-}$is favored $[9,10]$. Another previous study [12] indicates that the adduct can be particularly stable if the gas-phase basicity of $[\mathrm{A}]^{-}$is close to that of $[\mathrm{M}-\mathrm{H}]^{-}$.

Figure 2 shows the collision induced decomposition (CID) spectra of mass-selected fluoride and chloride adduct precursors of $\alpha$-D-glucose. The two experiments were performed under identical single collision conditions (collision cell argon gas pressure: $0.1-0.2$ mTorr) with low collision energies adjusted to nearly identical values $(2 \mathrm{eV})$ in the center-of-mass frame of reference $\left(\mathrm{E}_{\mathrm{com}}\right)$. From the decomposition patterns it can be concluded that: (1) The gas phase basicity of $\mathrm{F}^{-}$(1530 $\mathrm{kJ} / \mathrm{mol})[35,36]$ is larger than that of deprotonated $\alpha$-D-glucose as evidenced by the prominent peak at $m / z$ 179 (deprotonated $\alpha$-D-glucose) and the minor peaks $m / z 89$ and 119 (consecutive decomposition products of $m / z 179$ ), whereas $\mathrm{F}^{-}$at $m / z 19$ is not observed. (2) $\mathrm{Cl}^{-}$
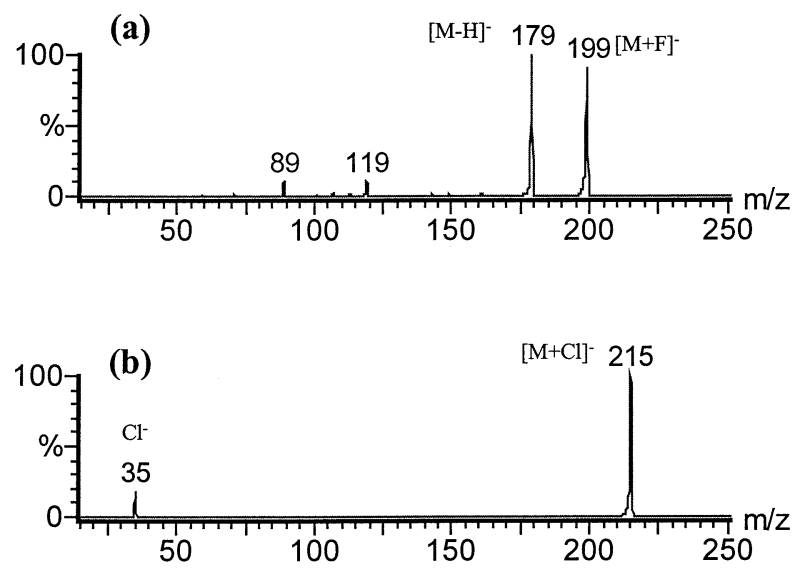

Figure 2. Collision induced decomposition (CID) mass spectra of $\alpha$-D-glucose (a) fluoride adduct, (b) chloride adduct. The collision energies were adjusted to nearly the same value $(2 \mathrm{eV})$ in the center-of-mass frame of reference.

has a lower gas-phase basicity $(1373 \mathrm{~kJ} / \mathrm{mol})[35,37,38]$ than that of deprotonated $\alpha$-D-glucose, as deduced by the observation of only $\mathrm{Cl}^{-}$at $\mathrm{m} / \mathrm{z} 35$ with no $[\mathrm{M}-\mathrm{H}]^{-}$ at $m / z$ 179. (3) The chloride adduct of $\alpha$-D-glucose is apparently more stable than the fluoride adduct as manifested by the reduced level of decomposition under the same collision conditions.

Particularities of the three-dimensional structure of the anionic adduct could also contribute to the stability of an adduct in the gas phase. Computer modeling is a good approach to visualize and evaluate the interaction between a neutral analyte and the attaching anion. For example, halide adducts of olefins [39] and chloride adducts of acetylene [40] have been studied recently via computational approaches. In the current study, computer modeling has been employed to provide information concerning which underlying forces are responsible for stabilizing a particular anionic adduct. $\alpha$-D-Glucose was examined as an exemplary monosaccharide and computational studies were performed on its fluoride, chloride, and bromide adducts. As one of the most important monosaccharides in nature, $\alpha$-Dglucose plays vital roles in the life processes of both plants and animals. The gas-phase and solution-phase properties of $\alpha$-D-glucose have been active areas for experimental [41-43] as well as theoretical studies [4250] for many years. Unambiguous nomenclature has been developed to describe the various conformers of neutral and deprotonated $\alpha$-D-glucose [45, 50]; this nomenclature is elaborated upon in the Appendix of this report. Figure 3 shows the final refined $\alpha$-D-glucose structure obtained by DFT B3PW91/6-311+G* calculation following the procedure described in the Experimental section of this report. This lowest energy conformer of $\alpha$-D-glucose is labeled $\alpha \mathrm{Gg} \overline{g g} g$ according to the nomenclature rules mentioned in the Appendix.

It should be noted that $\alpha \bar{G}$ and $\alpha \mathrm{T}$ are also lowenergy conformers of $\alpha$-D-glucose according to previous studies, and the energy difference between these 


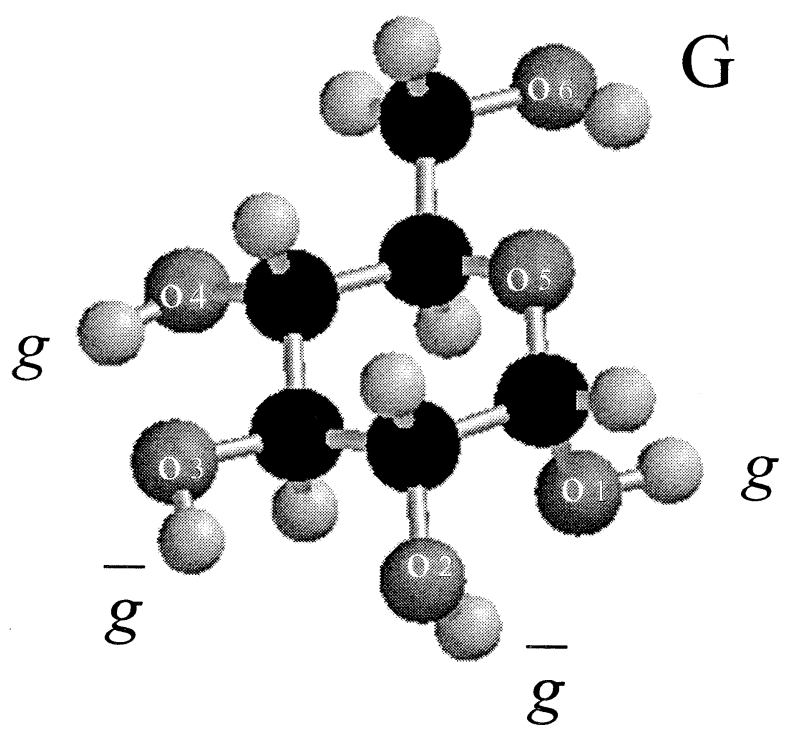

Figure 3. The lowest energy structure of $\alpha$-D-glucose optimized by density functional theory calculation at the level of B3PW91/ $6-311+\mathrm{G}^{*}$. This conformation is denoted as $\alpha \mathrm{Gg} g g g$.

conformers is very small (a few $\mathrm{kJ} / \mathrm{mol}$ ) $[42,49,50]$. However, the relative energy trends for the three conformers can vary depending upon the computational approach. The aim of our computational work is to better define the interaction between $\alpha$-D-glucose and attaching small inorganic anions. To achieve this, we use one lower-energy conformer as the model target, i.e., $\alpha \mathrm{Gg} g \overline{g g} g$ (Figure 3), that originated from a MMFF94 conformer search [27], rather than doing a complete $\alpha$-D-glucose conformer study via density functional calculations at the B3PW91/6-311+G* level.

Anionic adducts formed between $\alpha$-D-glucose and halide anions (fluoride, chloride and bromide) were examined at various levels of theory. For these halide adducts of $\alpha$-D-glucose, the initial structures were built via PC SPARTAN Plus version 2.0 on a template of $\alpha$-D-glucose that was geometry optimized by AM1. A halide anion was added arbitrarily in the space around the $\alpha$-D-glucose template to form an anionic system, then a MMFF94 conformer search was performed on the system followed by an AM1 optimization. It should be noted that the conformer search gave the same resultant adduct geometry regardless of the initial placement of the halide anion. The AM1 structure of the halide adduct of $\alpha$-D-glucose was then further optimized either by ab initio HF/6-31+ $\mathrm{G}^{*}$ calculation, or by DFT calculations at the B3PW91/6-311+ $\mathrm{G}^{*}$ level to get a more accurate picture of the geometry and the energy of the adduct. Figure 4 shows the most stable $\alpha$-Dglucose fluoride adduct structures obtained by AM1 (Figure $4 a$ ), ab initio HF/6-31+ $\mathrm{G}^{*}$ (Figure $4 \mathrm{~b}$, based on AM1 structure) and DFT B3PW91/6-311+ $\mathrm{G}^{*}$ (Figure 4c, based on AM1 structure) optimizations. In all three cases, fluoride forms hydrogen bonds with hydroxyl hydrogens on $\mathrm{C}(1)$ and $\mathrm{C}(2)$. Using the same procedure, we obtained structures of chloride and bromide ad- (a)

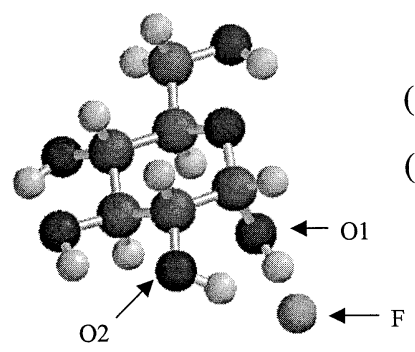

(C1)OH-F: $1.723 \AA$

(C2)OH-F: $1.722 \AA$

(b)

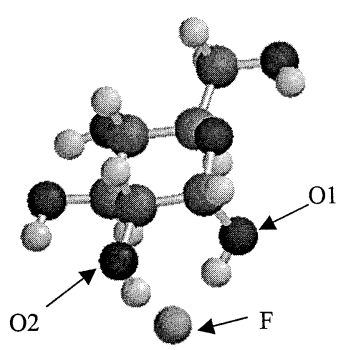

(C1)OH-F: $1.551 \AA$

(C2)OH-F: $1.599 \AA$

(c)

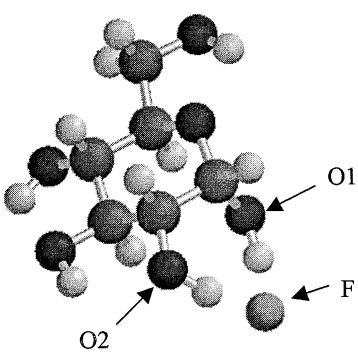

(C1)OH-F: $1.479 \AA$

(C2)OH-F: $1.464 \AA$

Figure 4. Preferred structures of fluoride adducts of $\alpha$-D-glucose optimized by (a) semi-empirical AM1, (b) ab initio HF 6-31+G*, (c) DFT B3PW91/6-311 $+\mathrm{G}^{*}$ calculations. In each case, fluoride forms hydrogen bonds with hydroxyl hydrogens on $\mathrm{C}(1)$ and $\mathrm{C}(2)$.

ducts of $\alpha$-D-glucose. These latter adducts each exhibited multiple hydrogen bonding between the attaching halide and $\mathrm{C}(1)$ and $\mathrm{C}(2)$ hydroxyl hydrogens. Structures involving multiple hydrogen bonding thus appear to be highly favored structures, and the additional interaction can substantially strengthen the binding of small inorganic anions to saccharides.

Monosaccharide units such as $\alpha$-D-glucose typically have more than two hydroxyl groups. These hydroxyl groups are located on a flexible backbone and the hydroxyl hydrogens are all eligible to form hydrogen bonds with a small inorganic anion. Clearly, saccharide adducts with small inorganic anions may exhibit a distribution of structures. In $\alpha$-D-glucose chloride attachment, the possibility for multiple hydrogen bonding in different geometries was studied by computational approaches. The three stable $\alpha$-D-glucose chloride adduct structures are illustrated in Figure 5. The structure in Figure 5a is analogous to the fluoride adducts shown in Figure 4 with interaction primarily at 
(a)
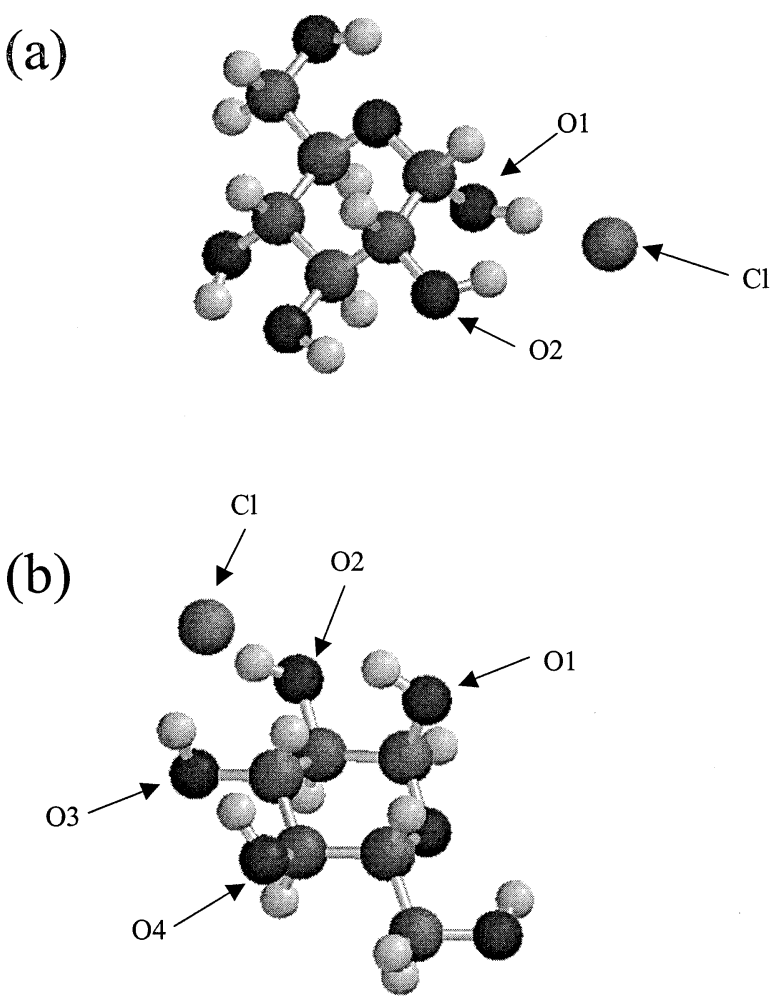

(c)

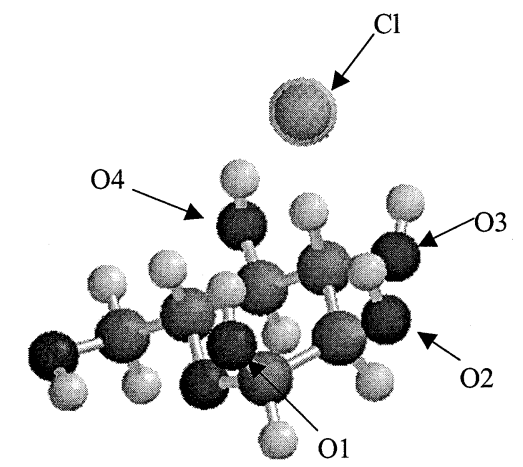

Figure 5. For chloride adducts of $\alpha$-D-glucose, the stability of adducts exhibiting multiple hydrogen bonding is confirmed by computational studies at the level of B3PW91/6-311+G*. (a) $\mathrm{Cl}^{-}$ forms hydrogen bonds with hydroxyl hydrogens on $\mathrm{C}(1)$ and $\mathrm{C}(2)$; (b) $\mathrm{Cl}^{-}$interacts with hydroxyl hydrogens on $\mathrm{C}(1), \mathrm{C}(2), \mathrm{C}(3)$, and $\mathrm{C}(4)$; (c) $\mathrm{Cl}^{-}$interacts with hydroxyl hydrogens on $\mathrm{C}(1), \mathrm{C}(2), \mathrm{C}(3)$, and $C(4)$. Total energy data obtained from B3PW91/6-311+ $\mathrm{G}^{*}$ calculations indicate that among the three structures, (c) is the most stable and (b) is the least stable. Interactions between anion and analyte at distances less than $2.5 \AA$ are particularly effective at stabilizing the anionic adduct.

the $C(1)$ and $C(2)$ hydroxyl hydrogens. The structure in Figure $5 \mathrm{~b}$ was built on an $\alpha$-D-glucose template with chloride linked by distance constraints to C(1) (3.48 $\AA$ ), $\mathrm{C}(2)(3.09 \AA)$, and C(4) (3.27 ̊̊) hydroxyl hydrogens. A MMFF94 conformer search followed by AM1 optimization was then performed on the initial structure. The final optimized structure and energy were obtained via DFT B3PW91/6-311+G* calculations without any added constraints using the AM1 optimized structure as the input file. The structure in Figure $5 \mathrm{c}$ was obtained in the same way except that in the initial structure, the chloride was linked by distance constraints to $C(1)$ (4.12 $\AA), C(2)(1.37 \AA), C(3)(2.57 \AA)$, and $C(4)(5.66 \AA)$ hydroxyl hydrogens. The multiple hydrogen bonds in the structures shown in Figure 5a, b, and c are described in Table 2. The three structures given in Figure 5 were particularly stable in lower level (AM1) calculations, and they were then elaborated upon at a higher computational level. (There are likely other stable structures for the chloride adduct of $\alpha$-D-glucose, because of the many possibilities for the chloride to interact with more than one of the five hydroxyl hydrogens of $\alpha$-D-glucose.)

Because multiple hydrogen bonding is a highly stabilizing form of interaction between the anion and the neutral analyte molecules, both in $\alpha$-D-glucose fluoride and chloride adducts, it certainly contributes to the survival of anionic adducts in the gas phase. The stability improvement gained by multiple hydrogen bonding, i.e., the stabilization energy, can be evaluated by examining the difference in "total energy" (electronic energy at $0 \mathrm{~K}$ ) between the anionic adduct and its decomposition products. Table 1 lists the total energies of the ions and neutral molecules involved in this study, calculated at the DFT B3PW91/6-311+G* level. The stabilization energy of the $\alpha$-D-glucose chloride adduct, for instance, can be evaluated by determining the total energy difference $(\Delta \mathrm{E})$ between the chloride adduct of $\alpha$-D-glucose and the sum of $\mathrm{Cl}^{-}$and neutral $\alpha$-Dglucose (products of the lowest energy decomposition pathway). In evaluating stabilization energies of the chloride adducts of $\alpha$-D-glucose shown in Figure 5, it is assumed that decomposition yields the most stable form of $\alpha$-D-glucose. The stabilization energies of the three forms of the chloride adduct of $\alpha$-D-glucose shown in Figure 5 are listed in Table 2.

For the $\alpha$-D-glucose fluoride adduct, the exact structure of the favored decomposition product $[\mathrm{M}-\mathrm{H}]^{-}$is somewhat ambiguous if one considers only the CID experiment. The stable adduct structures in Figure 4 indicate that fluoride forms hydrogen bonds with both $\mathrm{C}(1)$ and $\mathrm{C}(2)$ hydroxyl hydrogens. But either hydroxyl hydrogen could be lost (as HF) during adduct decomposition, thus leading to one of two isomeric forms of product $[\mathrm{M}-\mathrm{H}]^{-}$. In the absence of a reverse activation barrier to either decomposition, the energy difference between these two isomeric forms of $[\mathrm{M}-\mathrm{H}]^{-}$will determine which one would be the main product of adduct decomposition.

The structures and energies of the two isomeric forms of deprotonated $\alpha$-D-glucose were calculated via theoretical approaches similar to those mentioned above. The initial structures of deprotonated $\alpha$-D-glucose were obtained by removing the $C(1)$ or $C(2)$ hydroxyl hydrogen from an $\alpha$-D-glucose template, then a MMFF94 conformer search was performed on the deprotonated molecule, followed by AM1 optimization. 
(a)

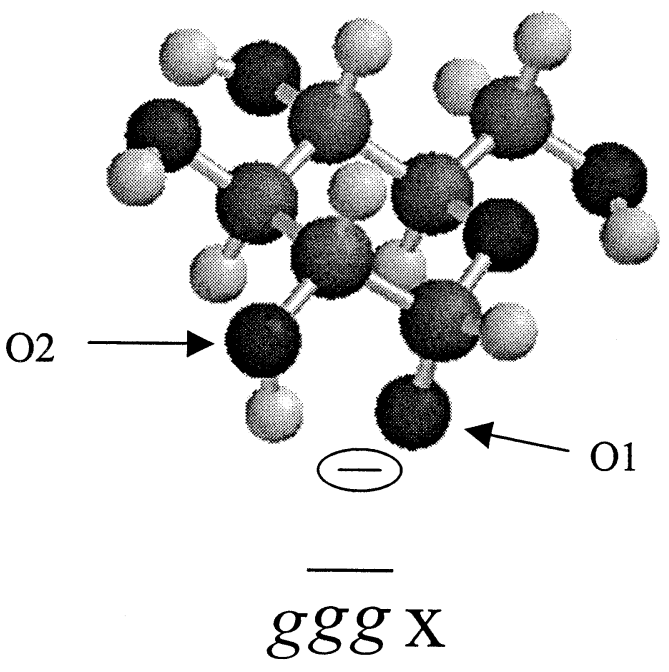

(b)

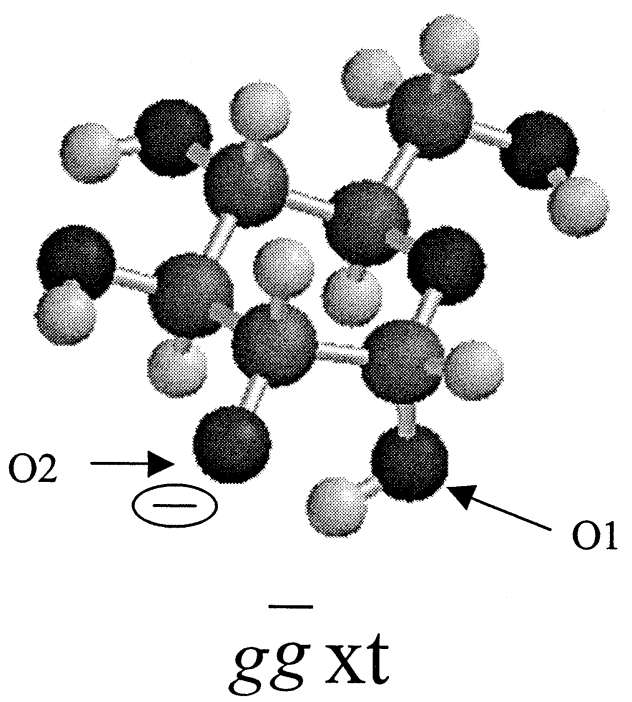

Figure 6. $\alpha$-D-glucose can undergo deprotonation most readily by departure of a hydroxyl hydrogen at either: (a) $\mathrm{C}(1)$ or (b) $\mathrm{C}(2)$. $A b$ initio HF $6-31+\mathrm{G}^{*}$ single point energy calculations based on AM1 geometry optimization indicate that structure (a) $\alpha \mathrm{G}_{1} g \overline{g g} x$ is more stable than structure (b) $\alpha \mathrm{G}_{2} g \bar{g} x t$ by $21.9 \mathrm{~kJ} / \mathrm{mol}$. The structure (a) and HF are the favored products of $\alpha$-D-glucose fluoride adduct decomposition at low energy.

The output structures of AM1 optimizations are shown in Figure 6. According to the notation rules set by Cramer and Truhlar [45] and Mulroney et al. [50], the structure shown in Figure 6a reflects deprotonation of the $\mathrm{C}(1)$ hydroxyl hydrogen and should be labeled as $\alpha \mathrm{G}_{1} g \overline{g g} x$; the structure given in Figure 6b reflects deprotonation of the $\mathrm{C}(2)$ hydroxyl hydrogen and should be labeled as $\alpha \mathrm{G}_{2} g \bar{g} x t$. Single point energy calculations at the level of $\mathrm{HF} / 6-31+\mathrm{G}^{*}$ have been performed on both structures. They indicate that $\alpha \mathrm{G}_{1}$ is more stable than $\alpha \mathrm{G}_{2}$ by $21.9 \mathrm{~kJ} / \mathrm{mol}$ in total energy. This result is consistent with previous theoretical studies at AM1 [48], HF/6-31G* [50], and B3LYP /6-31G* / HF/6-31G levels [50]. The structure of $\alpha \mathrm{G}_{1} g \overline{g g} x$ has been further optimized at the level of B3PW91/6-311+G*, and the total energy obtained for this conformer was applied as the energy of $[\mathrm{M}-\mathrm{H}]^{-}$in evaluating the stabilization energy of the fluoride adduct of $\alpha$-D-glucose relative to $[\mathrm{M}-\mathrm{H}]^{-}$and HF.

With the objective of addressing the question of whether significant reverse activation barriers exist, additional efforts were made to identify and characterize transition states for decompositions of halide adducts of $\alpha$-D-glucose listed in Table 2 using QST3 at the B3PW91/6-311 $+G^{*}$ level. It was found that, except for the decomposition of chloride adduct structure (a) (Figure 5a), none of the "transition states" exhibited displacement convergence, which suggests that they are not necessarily true saddle points on the potential energy surfaces. The fact that the forces have converged, but the displacements have not implies that these four potential energy surfaces exhibit certain flat regions along the decomposition reaction coordinate, wherein displacement in either direction causes little change in energy. The total energies of these "transition states" are shown in Table 1 . In comparing the $\Delta \mathrm{E}$ and the $\Delta \mathrm{E}^{\prime}$ values in Table 2 , it is evident that in all but one instance, the "transition state" has a lower energy than that of the decomposition product. For the one exception [Table 2, chloride adduct structure (c)], the two energies are virtually indistinguishable (143.4 versus $144.3 \mathrm{~kJ} / \mathrm{mol}$ ). These computational results suggest that there is no reverse activation barrier for these decompositions of halide adducts of $\alpha$-D-glucose that contain multiple hydrogen bonds. With no reverse activation barrier, the energy difference between the optimized adduct and the decomposition products in their most stable conformations can be used to directly evaluate the energy required for adduct decomposition along a given exit channel.

The energies of stabilization of $\alpha$-D-glucose halide adducts attributable to multiple hydrogen bonding between a halide anion and $\alpha$-D-glucose are equal to the negative of the $\Delta \mathrm{E}$ values listed for the reactions in Table 2 . In each case, the $\Delta \mathrm{E}$ was evaluated relative to the lowest energy dissociation pathway. In comparing the stabilization energies of the fluoride and chloride adducts of $\alpha$-D-glucose, it may be noted that the fluoride adduct has a stabilization energy similar to that of the most stable chloride adduct structure, but the tandem mass spectrometry results (Figure 2) indicate that the chloride adduct is significantly more stable than the fluoride adduct. The experimental stability trend for fluoride adducts versus chloride adducts seems to reflect the fact that the gas-phase basicity of chloride is closer than that of fluoride to the gas-phase basicity of 
$\mathrm{Glu}(\mathrm{C} 2) \mathrm{OH}-\mathrm{Cl}: 2.15 \AA$

$\mathrm{Glu}(\mathrm{C} 3) \mathrm{OH}-\mathrm{Cl}: 2.39 \AA$

$\mathrm{Fru}(\mathrm{C} 4) \mathrm{OH}-\mathrm{Cl}: 3.30 \AA$

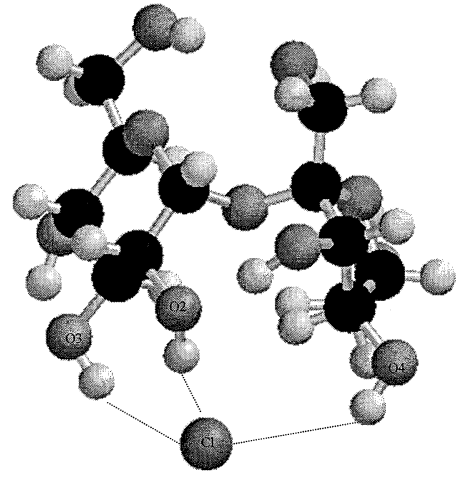

Figure 7. Structure of the chloride adduct of sucrose optimized at the $a b$ initio HF 3-21G level. In this conformer, chloride anion forms bridging hydrogen bonds with hydroxyl hydrogens on both the glucopyranosyl ring and the fructofuranosyl ring (indicated by dashed lines). The interactions between chloride and sucrose render the vulnerable glycosidic bond in sucrose more difficult to break.

deprotonated $\alpha$-D-glucose (1390 $\pm 15 \mathrm{~kJ} / \mathrm{mol})$ [12]. For adducts of the form $[\mathrm{M}-\mathrm{H}]^{-} \ldots \mathrm{H}^{+} \ldots[\mathrm{A}]^{-}$, a close matching of gas-phase basicities of the component anions has been shown to lead to improved adduct stability [12].

The chloride adduct of sucrose has exhibited exceptional stability at high cone voltages, conditions under which even the glycosidic bond undergoes significant decomposition (Figure 1). It is conceivable that chloride may form a type of "bridging" hydrogen bond with hydroxyl hydrogens on both the glucose ring and the fructose ring of sucrose. Such bridging multiple interactions have been affirmed in a previous theoretical study on alkali metal ion adducts of disaccharides [43]. To elucidate the geometry of the sucrose chloride adduct, one stable structure of the anionic adduct has been optimized via PC SPARTAN Plus version 2.0 (Figure 7). To obtain this conformer, first a sucrose template was built and roughly optimized by a MMFF94 energy minimizer. Then a chloride anion was added arbitrarily near the sucrose template with distance constraints linking the chloride to $\mathrm{C}(2)(4.06 \AA)$ and $\mathrm{C}(3)(4.51 \AA)$ hydroxyl hydrogens on the glucose ring and to $C(3)$ $(7.69 \AA)$ and C(4) (6.24 $\AA$ ) hydroxyl hydrogens on the fructose ring. A MMFF94 conformer search was then performed on the anionic system followed by an AM1 optimization. A further ab initio HF/3-21G optimization was performed on the AM1 optimized structure without any added constraints. The $a b$ initio HF/3-21G optimized structure in Figure 7 lends credence to the possibility that the stability of the anionic adduct is greatly enhanced by bridging multiple hydrogen bonds. This arrangement would strengthen the vulnerable glycosidic bond and can add stability to the chloride adducts which survive in Figure 1c.

Based on the above-mentioned ES-MS experimental and theoretical studies on the stability of small saccharide chloride adducts, we anticipate that such anionic adducts could also be observed in matrix-assisted laser desorption ionization mass spectrometry (MALDI-MS). The MALDI process is believed to transfer more energy to desorbed ions then electrospray, and anionic adduct species cannot readily survive [51]. Investigation of chloride anion attachment to saccharides via MALDI-MS is currently underway in our laboratory.

\section{Conclusion}

The equilibrium geometric structures of the lowest energy halide adducts of sucrose and $\alpha$-D-glucose have been studied via computational approaches. Anionic adducts of exceptional stability in ES mass spectra are shown to have gas-phase structures yielding very high stabilization energies in DFT calculations. The most stable anionic adducts of these saccharides are each characterized by multiple hydrogen bonding. Computational studies also reveal that chloride anion can form bridging hydrogen bonds between component monosaccharide rings of polysaccharides to stabilize the adducts and reduce the tendency for the vulnerable glycosidic bond to decompose.

\section{Acknowledgments}

The authors thank Dr. Peter Politzer for helpful discussions and for access to his group's computational facilities. They also thank Dr. Pat Lane for constructive input. This research was supported by the National Science Foundation through grant no. CHE9981948 and by the Louisiana Board of Regents through grant no. HEF(2001-06)-08.

\section{Appendix}

Cramer and Truhlar [45] set up a nomenclature convention to describe various conformer structures of $\mathrm{D}$ glucose in their theoretical analysis of glucose conformations in aqueous solution. In their study of relative gas-phase acidities of glucose, Mulroney et al. [50] applied a modified form of the Cramer-Truhlar nomenclature with added rules to describe conformers of deprotonated $\alpha$-D-glucose. For the hydroxyl hydrogens on $\mathrm{C}(1), \mathrm{C}(2), \mathrm{C}(3)$, and $\mathrm{C}(4)$ of the glucopyranose ring, the letter $\bar{g}$ [gauche(-)], t [anti], and g [gauche] were maintained in the Mulroney-Peel-Traeger (MPT) nomenclature to indicate the $\mathrm{H}-\mathrm{O}-\mathrm{C}(\mathrm{n})-\mathrm{C}(\mathrm{n}-1)$ dihedral angle. A $\bar{g}[$ gauche(-)] $\mathrm{OH}$ bond would need to be rotated approximately $60^{\circ}$ counterclockwise [viewed in the O-to- $\mathrm{C}(\mathrm{n})$ direction] in order to eclipse the bond to $\mathrm{C}(\mathrm{n}$ -1 ) or the ring $\mathrm{O}$, while the $g$ [gauche] $\mathrm{OH}$ bond would need to be rotated clockwise. The letter $\mathrm{x}$ was added in MPT nomenclature to substitute for $\bar{g}$, g, or $\mathrm{t}$ if the designated hydroxyl hydrogen is missing due to deprotonation. Figure 8 illustrates the $t, \bar{g}$, and g conformations of the anomeric [C(1)] hydroxyl group of $\alpha$-Dglucose.

The $\mathrm{C}(6)$ hydroxymethylene group has three possible orientations in $\alpha$-D-glucose. The letters $\mathrm{G}, \overline{\mathrm{G}}$, and T have been used to define these three hydroxymethylene 

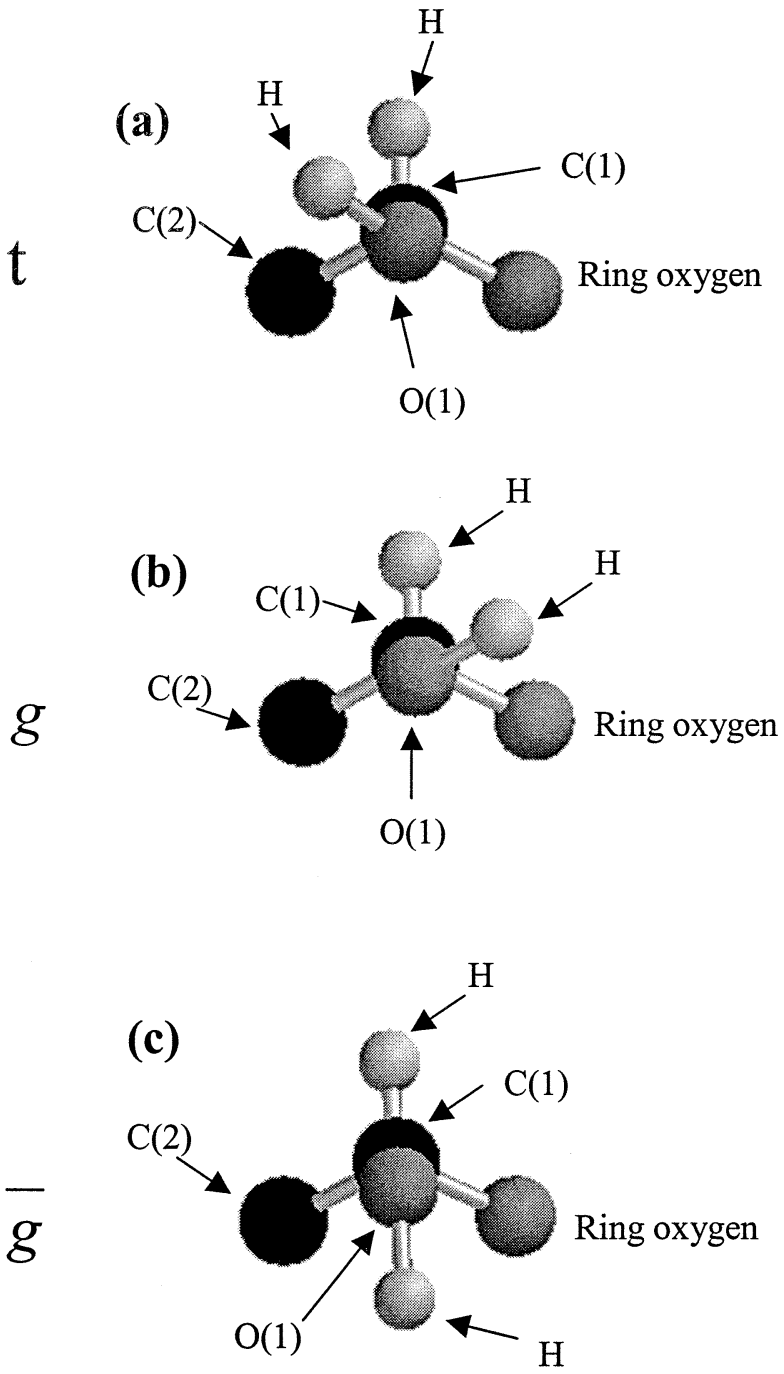

Figure 8. Possible conformations of the $\mathrm{C}(1)$ hydroxyl group of $\alpha$-D-glucose: (a) $t$; (b) $g$; (c) $\bar{g}$. For improved clarity, only C(1) (and attached hydrogen), $\mathrm{C}(2)$ and the ring oxygen atoms are shown.

conformers $[45,50]$, where $\mathrm{T}$ (trans) indicates that the hydroxymethylene oxygen $\mathrm{O}(6)$ is far from the ring oxygen $\mathrm{O}(5) ; \bar{G}$ designates that $\mathrm{O}(6)$ is closer to $\mathrm{O}(5)$, and the $\mathrm{O}(6)-\mathrm{C}(6)$ bond is almost perpendicular to the ring; $\mathrm{G}$ indicates that $\mathrm{O}(6)$ is closer to $\mathrm{O}(5)$, and the $\mathrm{O}(6)-\mathrm{C}(6)$ bond is almost coplanar with the ring. An example of a $\mathrm{C}(6)$ hydroxymethlene conformer designated as $\alpha \mathrm{G}$ is shown in Figure 3.

\section{References}

1. Ii, T.; Ohashi, Y.; Nagai, Y. Org. Mass Spectrom. 1993, 28 , 927-928.

2. Cheng, X.; Gao, Q.; Smith, R. D.; Simanek, E. E.; Mammen, M.; Whitesides, G. M. Rapid Commun. Mass Spectrom. 1995, 9, 312-316.

3. Harrison, K. A.; Murphy, R. C. J. Mass Spectrom. 1995, 30, 1772.

4. Zhu, J.; Li, Y.-T.; Li, S.-C.; Cole, R. B. Glycobiology 1999, 9(10), 985-993.

5. Peel, J. B. Aust. J. Phys. 1996, 49(2), 435-43.

6. Khairallah, G.; Peel, J. B. J. Phys. Chem. A 1997, 101(36), $6770-6774$.
7. Khairallah, G.; Peel, J. B. Chem. Commun. (Cambridge) 1997, 3(3), 253-254.

8. Khairallah, G.; Peel, J. B. Int. J. Mass Spectrom. 2000, 194(2/3), 115-120.

9. Cole, R. B.; Zhu, J. Rapid Commun. Mass Spectrom. 1999, 13, 607-611.

10. Zhu, J.; Cole, R. B. J. Am. Soc. Mass Spectrom. 2000, 11(11), 932-941.

11. Zhu, J.; Cole, R. B. J. Am. Soc. Mass. Spectrom. 2001, 12, 1193-1204

12. Cai, Y.; Cole, R. B. Anal. Chem. 2002, 74, 985-991.

13. Cooks, R. G.; Koskinen, J. T.; Thoma, P. D. J. Mass Spectrom 1999, 34, 85-92.

14. Gal, J.-F.; Maria, P.-C.; Raczyska, E. D. J. Mass Spectrom 2001, 36, 699-714.

15. Ervin, K. M. Chem. Rev. 2001, 101, 391-444.

16. Cheng, X.; Wu, Z.; Fenselau, C. J. Am. Chem. Soc. 1993, 115, $4844-4848$

17. Cerda, B. A.; Wesdemiotis, C. J. Am. Chem. Soc 1996, 118, 11884-11892.

18. Hofmeister, G. E.; Zhou, Z.; Leary, J. A. J. Am. Chem. Soc 1991, $113,5964-5970$.

19. Fuji, T. Mass Spectrom. Rev. 2000, 19, 111.

20. Burk, P.; Koppel, I. A.; Koppel, I.; Kurg, R.; Gal, J.-F.; Maria, P.-C.; Herreros, M.; Notario, R.; Abboud, J.-L. M.; Anvia, F.; Taft, R. W. Phys. Chem. A 2000, 104, 2824-2833.

21. Rodgers, M. T.; Armentrout, P. B. J. Am. Chem. Soc. 2000, 122, $8548-8558$.

22. Fura, A.; Leary, J. A. Anal. Chem. 1993, 65, 2805-2808.

23. Smith, G.; Leary, J. A. J. Am. Chem. Soc. 1998, 120, 13046-13056.

24. Yamashita, M.; Fenn, J. J. Phys. Chem. 1984, 88, 4671-4675.

25. Deppmeier, B. J.; Driessen, A. J.; Hehre, W. J.; Klunzinger, P. E.; Le T.; Yu J. PC SPARTAN Plus version 2.0; Wavefunction Inc.: Irvine, CA, 2000.

26. Halgren, T. A. J. Comput. Chem. 1996, 17, 490.

27. Hehre, W. J.; Deppmeier, B. J.; Klunzinger, P. E. PC SPARTAN Plus TUTORIAL version 2.0; Wavefunction, Inc.: Irvine, CA, 1999.

28. Dewar, M. J. S.; Reynolds, C. H. J. Comp. Chem. 1986, 2, 140.

29. Hehre, W. J.; Radom, L.; Schleyer, P. v. R.; Pople, J. A. Ab Initio Molecular Orbital Theory. Wiley: New York, 1986.

30. Frisch, M. J.; Trucks, G. W.; Schlegel, H. B.; Scuseria, G. E.; Robb, M. A.; Cheeseman, J. R.; Zakrzewski, V. G.; Montgomery, J. A. Jr.; Stratmann, R. E.; Burant, J. C.; Dapprich, S.; Millam, J. M.; Daniels, A. D.; Kudin, K. N.; Strain, M. C.; Farkas, O.; Tomasi, J.; Barone, V.; Cossi, M.; Cammi, R.; Mennucci, B.; Pomelli, C.; Adamo, C.; Clifford, S.; Ochterski, J.; Petersson, G. A.; Ayala, P. Y.; Cui, Q.; Morokuma, K.; Malick, D. K.; Rabuck, A. D.; Raghavachari, K.; Foresman, J. B.; Cioslowski, J.; Ortiz, J. V.; Stefanov, B. B.; Liu, G.; Liashenko, A.; Piskorz, P.; Komaromi, I. Gomperts, R.; Martin, R. L.; Fox, D. J.; Keith, T.; Al-Laham, M. A.; Peng, C. Y.; Nanayakkara, A.; Gonzalez, C.; Challacombe, M.; Gill, P. M. W.; Johnson, B.; Chen, W.; Wong, M. W.; Andres, J. L.; Head-Gordon, M.; Replogle, E. S.; Pople, J. A. Gaussian, Inc: Pittsburgh PA, 1998.

31. Becke, A. D. J. Chem. Phys. 1993, 98, 5648.

32. Perdew, J. P.; Wang, Y. Phys. Rev. B 1992, 37, 785.

33. Peng, C.; Ayala, P. Y.; Schlegel, H. B.; Frisch, M. J. J. Comp. Chem. 1996, 17, 49.

34. Wang, G.; Cole, R. B. In Electrospray Ionization Mass Spectrometry: Fundamentals, Instrumentation and Applications; Cole, R. B., Ed.; John Wiley and Sons, Inc.: New York, 1997; pp. 137-174.

35. Bartmess, J. E. Negative Ion Energies Data. In NIST Chemistry WebBook, NIST Standard Reference Database Number 69; Mallard, W. G.; Linstrom, P. J., Eds.; National Institute of 
Standards and Technology: Gaithersburg, 2000; (http:// webbook.nist.gov).

36. Blondel, C.; Cacciani, P.; Delsart, C.; Trainham, R. Phys. Rev. A $1989,40,3698$.

37. Martin, J. D. D.; Hepburn, J. W. J. Chem. Phys. 1998, 109, 8139-8142.

38. Fujio, M.; McIver, R. T., Jr.; Taft, R. W. J. Am. Chem. Soc. 1981, 103, 4017.

39. Hiraoka, K.; Katsuragawa, J.; Sugiyama, T.; Kojima, T.; Yamabe, S. J. Am. Soc. Mass Spectrom. 2001, 12, 144-149.

40. Meuwly, M.; Wolynec, P. P.; Bieske, E. J. J. Chem. Phys. 2002, $116,4948-4954$.

41. Nishida, Y.; Ohrui, H.; Meguro, H. Tetrahedron Lett. 1984, 25, 1575-1587.

42. Jebber, K. A.; Zhang, K.; Cassady, C. J.; Chung-Philips, A. J. Am. Chem. Soc. 1996, 118, 10515-10524.
43. Cerda, B. A.; Wesdemiotis, C. Int. J. Mass Spectrom. 1999, 189, 189-204.

44. Polavarapu, P. J.; Ewig, C. S. J. Comput. Chem. 1992, 13, 1255.

45. Cramer, C. J.; Truhlar, D. G. J. Am. Chem. Soc. 1993, 115, 5745-5753.

46. Salzner, U.; Schleyer, P. v. R. J. Org. Chem. 1994, 59, 2138.

47. Barrows, S. E.; Dulles, F. J.; Cramer, C. J.; French, A. D.; Truhlar, D. G. Carbohydr. Res. 1995, 276, 219.

48. Carroll, J. A.; Willard, D.; Lebrilla, C. B. Anal. Chim. Acta. 1995, 307, 431-447.

49. Brown, J. W.; Wladkowski, B. D. J. Am. Chem. Soc. 1996, 118, 1190-1193.

50. Mulroney, B.; Peel, J. B.; Traeger, J. C. J. Mass Spectrom. 1999, 34, 544-553.

51. Karas, M.; Glückmann, M.; Schäfer, J. J. Mass. Spectrom. 2000, 35, 1-12. 